\section{Transport organ physiology}

\section{O.H. Petersen}

Membrane Transport in Biology. Vol.IV A and B. Edited by G. Giebisch, D.C. Tosteson and H.H. Ussing. Pp.471; 939. (Springer: Berlin, Heidelberg and New York, 1979.) Two volumes DM296; $\$ 162.80$.

RECENT progress in the study of transport has been astonishing. This is clear when reviewing the impressive series on Membrane Transport in Biology, which has now been brought to an end with volume IV (consisting of two books) dealing with the transport organs. The editor of this last volume, Gerhard Giebisch (Yale), is to be congratulated on providing a number of good chapters written by scientists who are among the leaders in their fields of study. It was also a good idea to have asked Renkin (California) to provide an introductory chapter on transport across capillary membranes. However, while there is no denying the general high quality of the individual contributions, this volume is marred by an unfortunate lack of balance. Of the 18 chapters, no less than 10 deal exclusively with the kidney. In contrast, there are only two chapters on the intestine. Salivary glands, gastric secretion, exocrine pancreas, gall bladder and liver cells have one chapter each. This is clearly not a reasonable balance either in terms of current research interests or with respect to general importance. Furthermore, it means disturbingly uneven presentation with regard to depth of treatment and level of detail. Thus, while Boulpaep (Yale) devotes 47 pages exclusively to a discussion of kidney electrophysiology, Schultz (Houston) uses 31 pages in the only chapter on the small intestine and Schulz and Ullrich (Frankfurt) have 41 pages at their disposal to deal with all aspects of pancreatic membrane transport biology, including the electrophysiology! Nevertheless, Schulz and Ullrich's chapter on the pancreas is a model of clarity and also seems more up to date than many others, betraying the fact that the greater part of these two books must have been finished in late 1976 or early 1977 , although some more recent references seem to have been brought in at the proof stage.

The many chapters on kidney transport biology have their problems. In spite of separate chapters on electrochemistry (Khuri, Beirut) and electrophysiology, there is extensive repetition, particularly of the electrophysiology (even of some of the figures!) in chapters on sodium chloride (Windhager, Cornell) and potassium transport (Giebisch, Yale). One figure illustrating $\mathrm{Na}$-glucose co-transport in membrane vesicles (data of Kinne,
Frankfurt) is shown three times (pages 156, 426 and 555). The interaction between transport of sodium and organic solutes, originally discovered by Weymouth Reid at the turn of the century, rightly features prominently both in the kidney section, in an excellent review by Ullrich (Frankfurt), and in sections on the intestine and the pancreas.

Immediately following the massive kidney sections is a comprehensive chapter on the salivary glands by Young (Sydney). It is perhaps surprising that salivary glands should be much more extensively treated (more than 100 pages) than the stomach (Forte and Machen, California) or the pancreas, but at least we have here a very complete (up to 1977) account of the transport physiology of these glands. The completeness is, however, somewhat at the expense of clarity. It seems unlikely, for example, that the non-specialist will find the

\section{Autoradiographic techniques}

\section{Tim Appleton}

Techniques of Autoradiography. Third edition. By A.W. Rogers. Pp.429. (Elsevier/North-Holland: Amsterdam, New York and Oxford, 1979.) \$59; Dfl.133.

IT is always a difficult thing to write a book covering a wide range of techniques. Rogers has tackled his task with an infectious enthusiasm and I admire the courage and hard work which has gone into this work. Unlike the earlier editions, this edition is conveniently split into three main parts; the theoretical basis of autoradiography (129 pages); the planning and interpretation of autoradiographic experiments (151 pages); and description of autoradiographic techniques (126 pages). There is also a useful appendix of data which any autoradiographer will appreciate.

I wish I could be enthusiastic about this book. As with earlier editions the descriptions of techniques are mingled in with the text. It would be much more helpful to the beginner and expert alike if detailed descriptions of techniques were set out clearly in the form of a schedule, in heavy type-face, so that they can be easily found and followed. The chapter on photomicrography is not as helpful as it could be, because the quality of the illustrations is very poor - worse than in the first edition. I suspect that this may be the fault of the publisher, as some of the figures which are 'identical' with those in the first edition are clearly at a higher magnification in the third edition, yet the captions still show the lower
20 pages dealing with salivary gland electrophysiology (not a single illustration here!) easy going.

One cannot help wondering what readership the editor of this beautifully produced volume had in mind. The 10 very detailed kidney chapters must be attractive to nephrologists who might also enjoy the comparatively short but generally clear accounts of the other transport organs (or some of them; where is, for example, the placenta?). The title is, however, misleading, as it seems to announce a comprehensive treatment of membrane transport in the transport organs. What a pity that this last volume has only become a Membrane Transport Biology for nephrologists!

O.H. Petersen is Professor of Physiology at the University of Dundee, UK.

magnification. Figure 54 in the third edition is of the same field as figure 31 of the first edition; both figures show a magnification of $\times 135$, yet the third edition plates are magnified a further 1.4 times. Such errors are frequent and should have been noticed by the author at the proof stage. Considerable clarity has been lost in many of the illustrations and some of the line drawings are so faint in the review copy that they became irritating. Captions are frequently placed in awkward positions and orientations.

References throughout were fairly complete but did not give titles. Occasionally I found that the reference quoted was not always the authoritative one but taken from a symposium report or review. This resulted in some inaccuracy which might confuse the reader.

The first edition of this book appeared in 1967, was 335 pages long with 77 illustrations. The third, "completely revised", edition has grown to 429 pages with 98 illustrations. I thought that the first edition was too long and my immediate reaction to the latest edition is much the same. However, there is often some benefit in discussing techniques in such a lengthy manner; I found my interests in autoradiography rekindled as I read on. Such length is only really acceptible if the price can be kept at a reasonable level, and I fear that a cost of around $f 30$ will prove too high for the younger scientist.

It is inevitable that a book can never be up to date, and this is certainly true of this one. I would have liked to have seen more discussion of the use of scintillators to increase autoradiographic sensitivity, and on the localisation of diffusable substances at the level of the electron microscope. But then the book would have been even longer and, I fear, more expensive still.

Tim Appleton is Lecturer in Physiology at the University of Cambridge, UK. 